\title{
A LEITURA NA ESCOLA: AS CONTRIBUIÇÕES DE MIKHAIL BAKHTIN PARA A FORMAÇÃO DO LEITOR RESPONSIVO
}

\author{
Letícia Queiroz de CARVALHO \\ (Instituto Federal do Espírito Santo) \\ leticiaqc@hotmail.com
}

\begin{abstract}
Resumo: Por meio das contribuições teóricas do filósofo russo Mikhail Bakhtin, analisaremos neste artigo o papel do leitor nas práticas de leitura no contexto escolar, a fim de que possamos resgatar a postura responsiva e participante dos sujeitos envolvidos no trabalho com o texto ficcional, repleto de significados que não se esgotam entre a palavra escrita e o leitor. $O$ encontro entre a palavra e 0 sujeito que lê estabelece uma experiência que pode modificar a concepção que ambos têm do mundo e das suas próprias existências.
\end{abstract}

Palavras-chave: Literatura. Leitor. Linguagem e sociedade.

\section{READING IN SCHOOL: MIKHAIL BAKHTIN'S CONTRIBUTIONS TO THE EDUCATION OF RESPONSIVE READERS}

\begin{abstract}
By means of the dialogue with the theoretical contributions of the Russian philosopher Mikhail Bakhtin, we will analyze the of role of the reader in reading practices that take place in schools, in order to retrieve the responsive posture involved in working with the literary text, which isfull of meanings that do not end in the written word or in the reader. The meeting between the word and the subject who reads establishes an experience that can modify the vision both have of the world and of their own existences.
\end{abstract}

Keywords: Literature. Reader. Language and society. 


\section{Introdução}

Ao voltares às páginas do livro, ainda escutas o gemido da folhagem quando o vento lambia o seu esplendor.

João Pedro Mésseder

O trabalho com o texto literário torna-se significativo quando não ignoramos um dos seus mais relevantes aspectos: a experiência estética da leitura, a qual, no dizer de Cunha (1983), pode ser entendida como a soma da percepção/apreensão inicial de uma criação literária, além das inúmeras reações que esta pode suscitar em razão das especificidades postas em jogo pelo autor em sua edificação. Nesse jogo entre o texto e o leitor, a palavra escrita e quem a lê estabelecem uma interação a partir de uma experiência que pode ser bastante significativa, possibilitando, portanto, a condição para uma recepção estética da obra literária, em que o leitor tem um papel criativo a partir dos seus conhecimentos prévios, da sua sensibilidade e do contexto em que ele e a obra se inserem, tornando, pois, insubstituível o prazer proporcionado pelo contato direto com o livro.

O reconhecimento do leitor no processo de leitura também agregará novos valores e sentidos ao texto ficcional, possibilitando-Ihe uma postura ativa e crítica diante do texto e da vida. Portanto - quando pretendemos estabelecer diálogos entre a literatura, o leitor e a sociedade - não devemos perder de vista, segundo Pinheiro (2006), o princípio artístico, que é o fundamento de toda obra literária: a literatura é, antes de mais nada, arte; é um fenômeno de criatividade que representa o ser humano, o universo, a vida por meio da palavra, numa comunhão entre o sonho e a vida prática, entre a utopia e a realidade.

Em belíssima metáfora, Mário Quintana, compara o poema aos pássaros que pousam nas mãos do leitor, alimentam-se nelas (nas mãos que abrem e manuseiam os livros) e partem. $E$ dirigindo-se ao leitor, diz o sujeito lírico: “(...) $E$ olhas, então, essas tuas mãos vazias,/ no maravilhado espanto de saberes/que o alimento deles já estava em ti..."(QUINTANA, 1980)

A comparação metafórica de Quintana nos remete à importância do leitor no processo da leitura. O repertório intelectual, a sensibilidade e o lugar social desse leitor permitem a experiência estética com o texto literário e a possibilidade 
de manter viva, de alimentar com ideias e de perpetuar a obra literária. Sabemos que é no trabalho de parceria entre autor e leitor que existe a possibilidade de qualquer significação para o texto.

Geraldi (1988, p.7) destaca a participação ativa do leitor nesse processo, a partir da produção de significações decorrentes do seu trabalho intelectual no ato da leitura:

\begin{abstract}
Esta produção de significações é uma flecha em dois sentidos: ao ler, o leitor trabalha produzindo significações e é nesse trabalho que ele se constrói como leitor. Suas leituras prévias, sua história de leitor, estão presentes como condição de seu trabalho de leitura e esse trabalho o constitui leitor e assim sucessivamente.
\end{abstract}

Por isso, a partir das contribuições teóricas do filósofo russo Mikhail Bakhtin, analisaremos o papel do leitor nas práticas de leitura no contexto escolar, a fim de que possamos resgatar a postura responsiva e participante dos envolvidos no ato de ler, por entendermos que o ato de leitura está repleto de significados que não se esgotam entre a palavra escrita e o leitor. O encontro entre a palavra e o sujeito que lê estabelece uma experiência que pode modificar a concepção que ambos têm do mundo e das suas próprias existências.

Estranhamento, surpresa, ruptura, imprevisibilidade, incômodo e tantos outros sentimentos são necessários para que o leitor problematize a realidade que o circunda e faça do contato com os livros uma prática também de experiência coletiva inserida na dimensão histórica.

Por seu caráter plural, polissêmico e conotativo, a palavra no texto literário pressupõe uma postura aberta ao diálogo, afinal, como lembra Antenor Filho (2002, p.13):

(...) a literatura não se situa no território de sombras de uma tradição de cultura falida - algo feito para fruição e enfeite: ela é conhecimento produzido historicamente, além de ocupar, na prática cultural, um lugar de privilégio como exercício de liberdade, de inquietação e de perplexidade.

Em nossas práticas, ainda repletas de fissuras entre o que teorizamos e 0 que podemos fazer com os livros e a leitura em suas múltiplas vertentes na escola, a mediação do professor é fundamental para que os envolvidos no processo de leitura reconheçam o plurilinguismo presente no texto literário, que se reinventa em cada contexto no qual é lido e significado, devendo, pois, ser lido de forma ativa, para além das convenções linguísticas. Portanto, um bom texto 
resiste ao tempo e está sempre convidando o leitor para revitalizá-lo e agir sobre ele. (BAKHTIN, 1993)

Essa perspectiva de trabalho pode ser bastante fecunda se buscarmos algumas articulações entre a concepção do filósofo russo Mikhail Bakhtin sobre a linguagem e as nossas atividades pedagógicas presentes nas aulas de Literatura, porque

Sob a ótica bakhtiniana, é no fluxo da interação verbal que a palavra se concretiza como signo ideológico, que se transforma e ganha diferentes significados, de acordo com o contexto em que ela surge. Dessa forma, constituído pelo fenômeno da interação social, o diálogo revela-se como a tessitura da vida pela linguagem. (KRAEMER, 2006, p.4)

Buscaremos, desse modo, algumas relações entre o aspecto dialógico presente na linguagem literária e as atividades de leitura propostas no ambiente escolar, para que possamos compreender e assimilar novas formas de trabalho com o texto ficcional.

\section{1 - Mikhail Bakhtin e a formação do leitor: diálogos possíveis}

Tudo se reduz ao diálogo, à contraposição dialógica enquanto centro. Tudo é meio, o diálogo é o fim. Uma só voz nada termina, nada resolve. Duas vozes são o mínimo de vida.

Mikhail Bakhtin

A importância da leitura nas escolas e seus efeitos sociais não são temas novos e têm sido objeto de pesquisa em inúmeros trabalhos acadêmicos e projetos sociais. No entanto, por mais que esse tema invada insistentemente 0 cenário educacional, ainda não percebemos como prática escolar constante um trabalho cultural com o texto literário que dialogue com aspectos da vida social e que envolva o jovem leitor nesse processo dialógico.

Como o cotidiano escolar é também um campo de tensões permanentes, um dos possíveis motivos apresentados pelos jovens em relação ao desinteresse pela leitura é o fato dessa prática não fazer sentido em suas vidas. Kleiman afirma: "Ninguém consegue fazer aquilo que é difícil demais, nem aquilo do qual não consegue extrair sentido", portanto, cabe ao professor "negociar para poder ensinar a ler", é preciso quebrar barreiras da resistência do próprio aluno. (KLEIMAN, 2001, p.16). Lajolo também afirma que todas "as atividades escolares 
das quais o texto participa precisam ter sentido, para que o texto resguarde seu significado maior." (LAJOLO, 1998, p. 62).

Desse modo, nós, professores, podemos estimular a interlocução entre nossos alunos-leitores e o texto, de modo que eles criem uma postura ativa diante do que lêem, estabelecendo conexões entre o passado e o presente, no sentido de que a leitura seja uma atividade reflexiva e consciente.

Quando o texto literário extrapola as questões técnicas e específicas que o circundam e dialoga com a vida e as questões sociais, a partir de contextos significativos de leitura imbricados com o real, temos, então, o verdadeiro sentido de ler e, constituímos, pois, nossa memória intertextual como leitores ativos.

Assim, a partir de uma perspectiva bakhtiniana, na atividade de leitura, não existe destinatário abstrato, tampouco o texto pode ser visto apenas como um produto cultural fechado a múltiplas interpretações em um processo de compreensão passiva. $\mathrm{O}$ ato de leitura não corresponde a apenas reproduzir a fala do autor, mas, a partir do horizonte social e das concepções do leitor, tomar uma atitude responsiva ativa.

A leitura como ato de constituição do sentido faz parte de um permanente conflito de vozes entre o texto, o autor, o leitor, as outras vozes sociais e o próprio mundo histórico-social que circunda todos os envolvidos no processo. Logo, a leitura constrói-se justamente no 'diálogo', na fronteira entre essas diversas vozes que circundam o texto, afinal,

O diálogo, no sentido estrito do termo, não constitui, é claro, senão uma das formas, é verdade que das mais importantes, da interação verbal. Mas pode-se compreender a palavra "diálogo" num sentido amplo, isto é, não apenas como a comunicação em voz alta, de pessoas colocadas face a face, mas toda comunicação verbal, de qualquer tipo que seja. (BAKHTIN, 2006, p.117)

Para Bakhtin o sujeito constitui-se em relação ao outro. Isto significa, como nos lembra Fiorin (2006), que o dialogismo é o princípio de constituição do indivíduo e o seu princípio de ação, uma vez que a consciência constrói-se na comunicação social, ou seja, na sociedade, na História. Desse modo, o mesmo autor reitera que o sujeito vai se construindo discursivamente, aprendendo as vozes sociais que constituem a realidade em que está imerso.

Nessa aprendizagem, o sujeito torna-se constitutivamente dialógico por não absorver apenas uma voz social, mas várias, que estão em relações diversas 
entre si, em relações de concordância ou discordância. O encontro dessas vozes com o contexto em que estão inseridas caracteriza, pois, o dialogismo como o fenômeno que ocorre em todo e qualquer discurso, que por sua vez é uma resposta a outro discurso, portanto um entrecruzamento de pensamentos. $A$ compreensão de um texto, por isso, permite o diálogo com esse mesmo texto, com o escritor e com outros textos similares já lidos pelo leitor. Com isso, dizemos que a leitura de uma obra é uma atividade sóciocultural.

A Literatura, portanto, relaciona-se ao contexto social mais amplo, não apenas como componente curricular, mas, principalmente, como importante elemento cultural que integra as relações e atividades humanas, para além da escolarização das suas produções.

Disto se seguem importantes questões para o trabalho com a Literatura no contexto escolar: que relações estabelecemos com nossos alunos no ato de leitura? A leitura na escola tem se constituído espaço de interação entre as múltiplas vozes que compõem o cenário social? Qual a importância da escolarização da leitura para a formação do leitor ativo? A partir dos livros temos possibilitado um diálogo entre a literatura e o universo dos nossos alunos? Qual a relação entre a Literatura e a construção de alguns valores sociais?

Muitas outras questões poderiam ser levantadas no contexto das atividades literárias, se pensarmos na leitura como uma atividade dinâmica de permanente construção e reconstrução de sentidos, não apenas para os alunos, mas também para o professor que, em um processo dialógico, revê suas práticas na mediação com os outros sujeitos com os quais interage.

Sabemos que as atividades de leitura devem superar padrões ou regras estabelecidas para que provoquem o espanto, a inquietação, a dúvida, a perplexidade e, principalmente, o encontro com o outro, afinal

(...) sabemos que ler não é apenas decodificar, é compreender e, mais ainda, é indagar, deduzir, inferir, associar, intuir, prever, concluir, discordar, concordar, acrescentar, selecionar, entre outras formas de interpretar e fruir um texto. Só percebendo que a leitura possibilita tudo isso é que se pode ter plena consciência de sua importância na formação intelectual, cultural e social dos indivíduos. (CORRÊA, 2003, p.53)

Para Bakhtin (2006), a palavra permite que nos definamos em relação ao outro e à coletividade, afinal, por comportar duas faces, essa palavra se determina tanto por proceder de alguém, como pelo fato de se dirigir para alguém, 
sendo, pois, o produto da interação entre o locutor e o ouvinte, ou seja, o seu território comum.

Matéria-prima do texto literário, a palavra, na perspectiva bakhtiniana, traduz-se como ponte entre o texto, leitores, autores e o mundo. Ler, portanto, ultrapassa as expectativas meramente técnicas ou utilitaristas no universo escolar e assume uma dimensão social, concreta e inclusiva, já que o autor, a obra, os professores e os alunos-leitores se constituem no exercício permanente do diálogo e das infinitas descobertas que o livro lhes pode oferecer.

As atividades de leitura passam a ser vivas, emancipatórias e, por que não dizer, sedutoras, uma vez que significam ir além das pretensões moralizantes e dogmáticas para adentrarem os conflitos e os paradoxos próprios da condição humana. Nesse processo dialógico de leitura, o leitor constitui-se em meio às transgressões da própria língua, trata de assuntos que permeiam sua realidade histórica, encontra na linguagem metafórica e nos recursos expressivos da linguagem literária a fenda necessária para se sobrepor à rigidez das prescrições inevitáveis da vida.

Bakhtin pressupõe natural a atitude responsiva do leitor em um processo de enunciação vivo, porque

[...] toda compreensão de uma fala viva, de um enunciado vivo, é sempre acompanhada de uma atitude responsiva ativa (conquanto o grau dessa atividade seja muito variável); toda compreensão é prenhe de resposta e, de uma forma ou de outra, forçosamente a produz: o ouvinte torna-se o locutor (BAKHTIN, 1997, p.290).

O ato de ler, por ser uma prática social construída em meio a interações verbais dos sujeitos que a constituem, pressupõe espaços de interlocuções entre autores, leitores e professores - mediadores do processo - de modo que as experiências, os repertórios intelectuais e os discursos de toda essa comunidade leitora se cruzem nessa atividade real e heterogênea da linguagem, na qual os enunciados também heterogêneos possam caracterizar um espaço em que várias vozes sociais possam se opor, se contradizer e revelar as diferentes formações sociais que permeiam os discursos que ali se encontram.

Nessa perspectiva de trabalho com o texto literário, não há como ignorar a relação entre a linguagem literária e os recursos expressivos que a caracterizam e os valores socioculturais próprios do contexto de produção da obra, sempre em 
diálogo com o momento histórico em que vivem os seus leitores, sujeitos que agregarão à leitura novas significações, a partir dos seus valores e concepções.

Desse modo, um leitor participativo e crítico torna-se sensível aos milhares de Fabianos e Sinhás Vitórias que vivem até hoje, miseravelmente, no sertão nordestino; às Macabéas solitárias, silenciosas e silenciadas pela dureza da vida; aos Josés drummondianos que seguem errantes em seu tempo, sem perspectiva, perplexos diante das transformações sociais; aos Brás Cubas subversivos e malandros, tão humanos, tão julgados e incompreendidos e com tantos outros inesquecíveis personagens que vagam anônimos em nosso tempo.

Sob a ótica bakhtiniana, a leitura constitui-se no processo de interação verbal, mediada pelo livro e por seus interlocutores ativos, constituídos por sua vez, pelas suas histórias de vida, valores, experiências, medos, desejos, contradições, indignações e, principalmente, por suas realidades históricas concretas.

O livro, objeto cultural da leitura, para além dos anseios mercadológicos e estéticos, traz em seu bojo o eco de muitas vozes, de muitos tempos, de muitas histórias e estórias que se tornam perenes nas mãos de bons leitores, os quais perpetuam esse universo ficcional por muitas gerações que recriarão novas histórias, novos textos e, quiçá, novos livros, afinal, para o filósofo russo

\begin{abstract}
O livro, isto é, o ato de fala impresso, constitui igualmente um elemento da comunicação verbal. Ele é objeto de discussões ativas sob a forma de diálogo e, além disso, é feito para ser apreendido de maneira ativa, para ser estudado a fundo, comentado e criticado no quadro do discurso interior, sem contar as reações impressas, institucionalizadas, que se encontram nas diferentes esferas da comunicação verbal (críticas, resenhas, que exercem influência sobre os trabalhos posteriores, etc.). Além disso, o ato de fala sob a forma de livro é sempre orientado em função das intervenções anteriores na mesma esfera de atividade, tanto as do próprio autor como as de outros autores: ele decorre portanto da situação particular de um problema científico ou de um estilo de produção literária. Assim, o discurso escrito é de certa maneira parte integrante de uma discussão ideológica em grande escala: ele responde a alguma coisa, refuta, confirma, antecipa as respostas e objeções potenciais, procura apoio, etc. (BAKHTIN, 2006, p.118)
\end{abstract}

Como elemento da comunicação verbal, o livro é constituído por enunciados que, independentes da sua dimensão, são dialógicos por trazerem em seu bojo a palavra dialogizada, sempre atravessada pela palavra do outro. Enquanto as unidades da língua são neutras e não são dirigidas a ninguém, os enunciados têm um destinatário e carregam consigo emoções, opiniões, valores e crenças. Quando a palavra é assumida por alguém e ganha um acabamento específico, ela se converte em enunciado e, portanto, passa a ser dirigida a 
alguém. Os enunciados têm sentido, que é sempre de ordem dialógica, enquanto as unidades linguísticas podem ser compreendidas em relação às outras unidades estruturais com as quais se relacionam no texto. (BAKHTIN, VOLOCHINOV, 2006)

Todo enunciado é dialógico, pois se constitui a partir de outro enunciado, pois nele ouvem-se sempre, ao menos, duas vozes. Portanto, o dialogismo, na concepção de Bakhtin, que pode ser considerado como o modo de funcionamento real da linguagem, é o princípio constitutivo do enunciado. Fiorin (2006), ao analisar os aspectos dialógicos da linguagem sob a ótica bakhtiniana anuncia a importância da sala de aula para o desenvolvimento das atividades de linguagem

Diante disto, entendo que a sala de aula é um lugar de encontro de diferentes vozes, as quais mantêm relações de controle, negociação, compreensão, concordância, discordância, discussão. Neste espaço, a aprendizagem é uma atividade social de construção em conjunto, resultante das trocas dialógicas, uma vez que, na perspectiva bakhtiniana, o significado não é inerente à linguagem, mas elaborado socialmente.

Torna-se muito importante, desse modo, a compreensão da natureza social das práticas de leitura para a formação do leitor responsivo. Realizar leituras na perspectiva de construção conjunta de significados, em meio às discordâncias, conflitos, concordâncias, afinidades, diferenças culturais e mediações que considerem a multivocalidade discursiva nos enunciados que constituem o texto literário é um imperativo em tempos de novos suportes textuais que invadem o cenário social.

Novos suportes demandam novas linguagens, novos leitores, novos valores e mediações mais flexíveis para o trabalho com a literatura. Não se admitem mais leituras que cumpram apenas rotinas pedagógicas e sequer preparem o aluno para pensar questões urgentes do seu tempo, relacionadas ao seu posicionamento individual e coletivo na esfera em que vive socialmente.

Se pensarmos a leitura também como um processo de comunicação, independentemente de sua dimensão, perceberemos que os enunciados que a permeiam - sejam da obra, sejam das discussões e debates advindos do texto, sejam da mediação feita pelo professor, sejam de outros textos com os quais se relacionam - são dialógicos. Nos enunciados que emergem dessas práticas estão presentes ecos e lembranças de outros enunciados. Fiorin (2006) ressalta que, enquanto as unidades da língua são neutras e não têm autoria, uma vez que 
qualquer um pode falar uma palavra, um enunciado por sua vez, tem um autor: "Fulano disse que..."

O estímulo à participação de nossos alunos como sujeitos portadores de enunciados, a partir do confronto entre a leitura na perspectiva dialógica e os seus valores, crenças e concepções sociais, pode ser um exercício interessante para a formação do leitor responsivo e ativo, o qual buscará sempre estabelecer conexões entre o seu mundo, a sua palavra e o mundo e a palavra do outro, com o qual compartilha, diverge, concorda, aprende e ensina um pouco do que leu nos livros e na vida.

Para além das leituras redutoras, obrigatórias e impositivas, o leitor inserido em práticas dialógicas de leitura saberá estabelecer relações entre a ficção e o mundo concreto; sentir-se-á parte integrante da dinâmica social e sujeito vivo em seu tempo, leitor do mundo - no sentido freireano - porque, como lembra Lajolo (2001), a Literatura é porta para variados mundos que nascem das várias leituras que dela se fazem. Os mundos que ela cria permanecem no leitor, incorporados como vivência, marcos da história de leitura de cada um.

\section{Referências bibliográficas}

BAKHTIN, Mikhail. Questões de literatura e de estética - A teoria do romance. São Paulo: UNESP-HUCITEC, 1993. P.71-210

BAKHTIN, M. M. e VOLOCHÍNOV, V. N. Marxismo e filosofia da linguagem. São Paulo: HUCITEC, 2006.

BAKHTIN, Mikhail. Estética da criação verbal. São Paulo: Martins Fontes, 1997.

CORRÊA, Hércules Tolêdo. "Adolescentes leitores: eles ainda existem." In: Literatura e letramento: espaços, suportes e interfaces. 0 jogo do livro. PAIVA, Aparecida; EVANGELISTA, Aracy Alves Martins; PAULINO, Graça; MACHADO, Maria Zélia Versiani (Orgs). Belo Horizonte: Autêntica, 2003.

CUNHA, M. A. A. Literatura Infantil: Teoria e Prática. São Paulo: Ática, 1983.

FILHO, Antenor Antônio Gonçalves. Educação e literatura. Rio de Janeiro: DP \&A, 2002.

FIORIN, José Luiz. O dialogismo. In: Introdução ao Pensamento de Bakhtin. São Paulo: Ática, 2006. P.18 -59. 
GERALDI, João Wanderley. A leitura na sala de aula: as muitas faces do leitor. Série Idéias n.5. São Paulo: FDE, 1988. p.79-84.

KLEIMAN, A. Oficina de leitura: teoria e prática. 8. ed. São Paulo: Pontes, 2001.

KRAEMER, Márcia Adriana Dias. Ensino gramatical de língua materna: uma arena de conflitos. REVISTA LETRA MAGNA. Revista Eletrônica de Divulgação Científica em Língua Portuguesa, Lingüística e Literatura - Ano 03- n.04 -1ํㅡㄴ Semestre de 2006

LAJOLO, Marisa. Literatura: leitores \& leitura. São Paulo: Moderna, 2001. O texto não é pretexto. In: ZILBERMAN, R. et al. (Org.). Leitura em crise na escola: as alternativas do professor. 9. ed. Porto Alegre: Mercado Aberto, 1998.

PINHEIRO, Carlos Eduardo Brefore. Literatura em sala de aula: a dinâmica da construção do conhecimento. Texto disponível em:

http://www.portrasdasletras.com.br/pdt|2/sub.php?op=literatura/docs/literatura em sala

QUINTANA, Mário. "Os poemas". In: Esconderijos do tempo. Porto Alegre: $L$ \& PM Editores, 1980. 
Artigo recebido em: 21 de março de 2015

Artigo aprovado em: 25 de março de 2015

Sobre a autora:

Letícia Queiroz de Carvalho é professora dos cursos técnicos integrados, concomitantes, superiores e de pós-graduação lato sensu de Administração e de Eletromecânica do IFES - Campus Guarapari. A partir de 2014, passou a atuar como docente na Graduação em Letras à distância e no Mestrado Profissional em Letras, do campus Vitória. 